\title{
Intimal Dissection Of Blood Vessel
}

National Cancer Institute

\section{Source}

National Cancer Institute. Intimal Dissection Of Blood Vessel. NCI Thesaurus. Code C50616.

A dissection of an artery that occurs though a tear in the inner lining of the blood vessel. 